\title{
Formation of Oligomers in Secondary Organic Aerosol
}

Michael P. Tolocka ${ }^{1}$, Myoseon Jang ${ }^{2}$, Joy M. Ginter ${ }^{1}$, Frederick J. Cox ${ }^{1}$, Richard M. Kamens ${ }^{2}$

and Murray V. Johnston ${ }^{1} *$

Department of Chemistry and Biochemistry, University of Delaware.

AUTHOR EMAIL ADDRESS: mvj@udel.edu

\section{Environmental Science and Technology}

\section{Supporting Information}

Figure S1. Product ion spectrum of the $359 \mathrm{~m} / \mathrm{z}$ precursor from dimerization of pinonaldehyde

Figure S2. A) Calculated $\mathrm{m} / \mathrm{z}$ values and number of combinations for dimers produced by direct coupling of two monomers (primary ozonolysis products). B) Calculated $\mathrm{m} / \mathrm{z}$ values and number of combinations for dimers proudcted by direct coupling of two monomers and trimers produced from one or two monomers in combination with two or one monomer decomposition products (Scheme 1b).

Figure S3. Mass spectrum of ambient aerosol collected at Research Triangle Park, NC

Figure S4. Product ion spectrum of the $359 \mathrm{~m} / \mathrm{z}$ precursor from ambient aerosol collected at Research Triangle Park, NC 
es035030r-Supporting Information

page $\mathrm{S} 2$

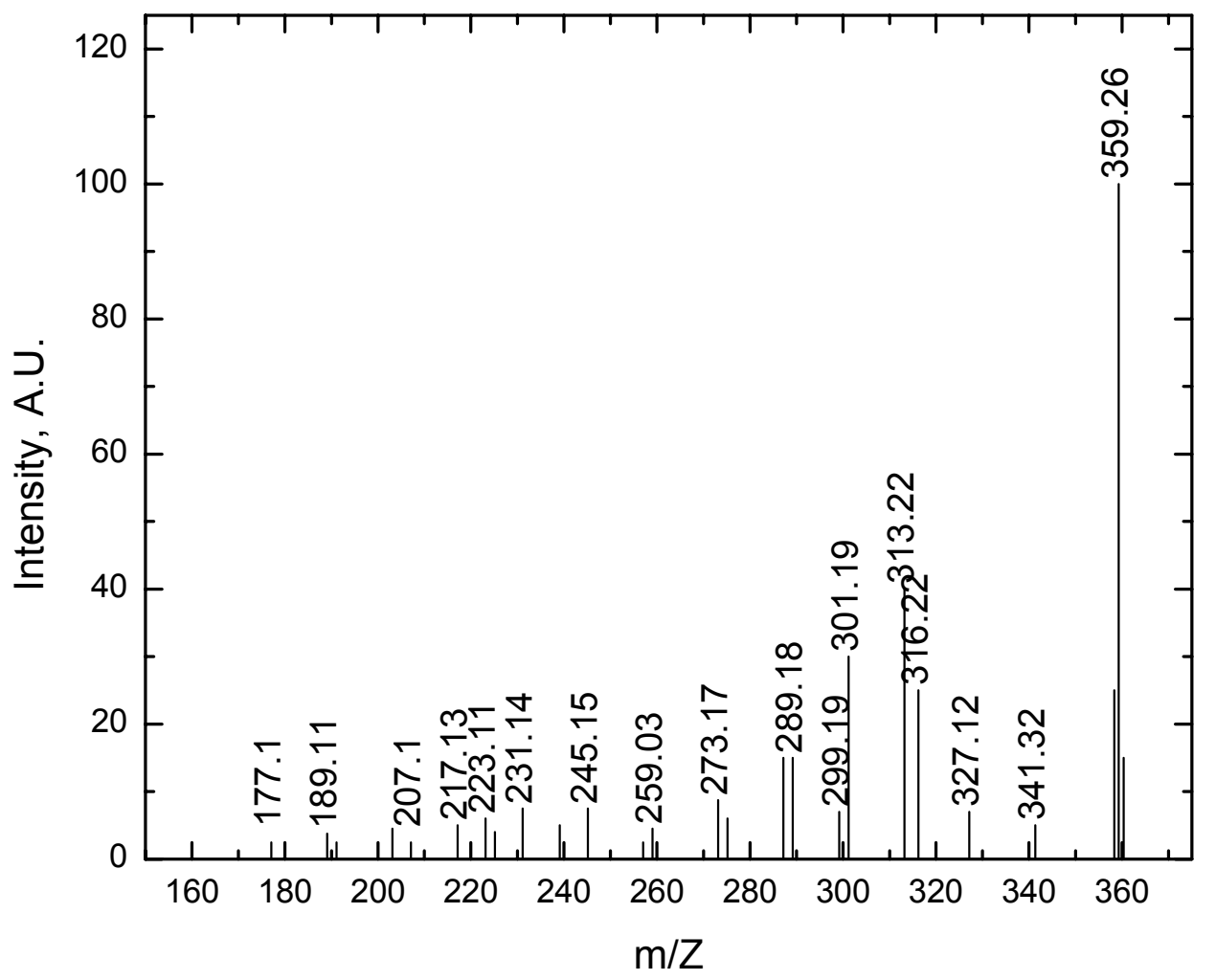

Figure S1. 
es035030r-Supporting Information

page $\mathrm{S} 3$
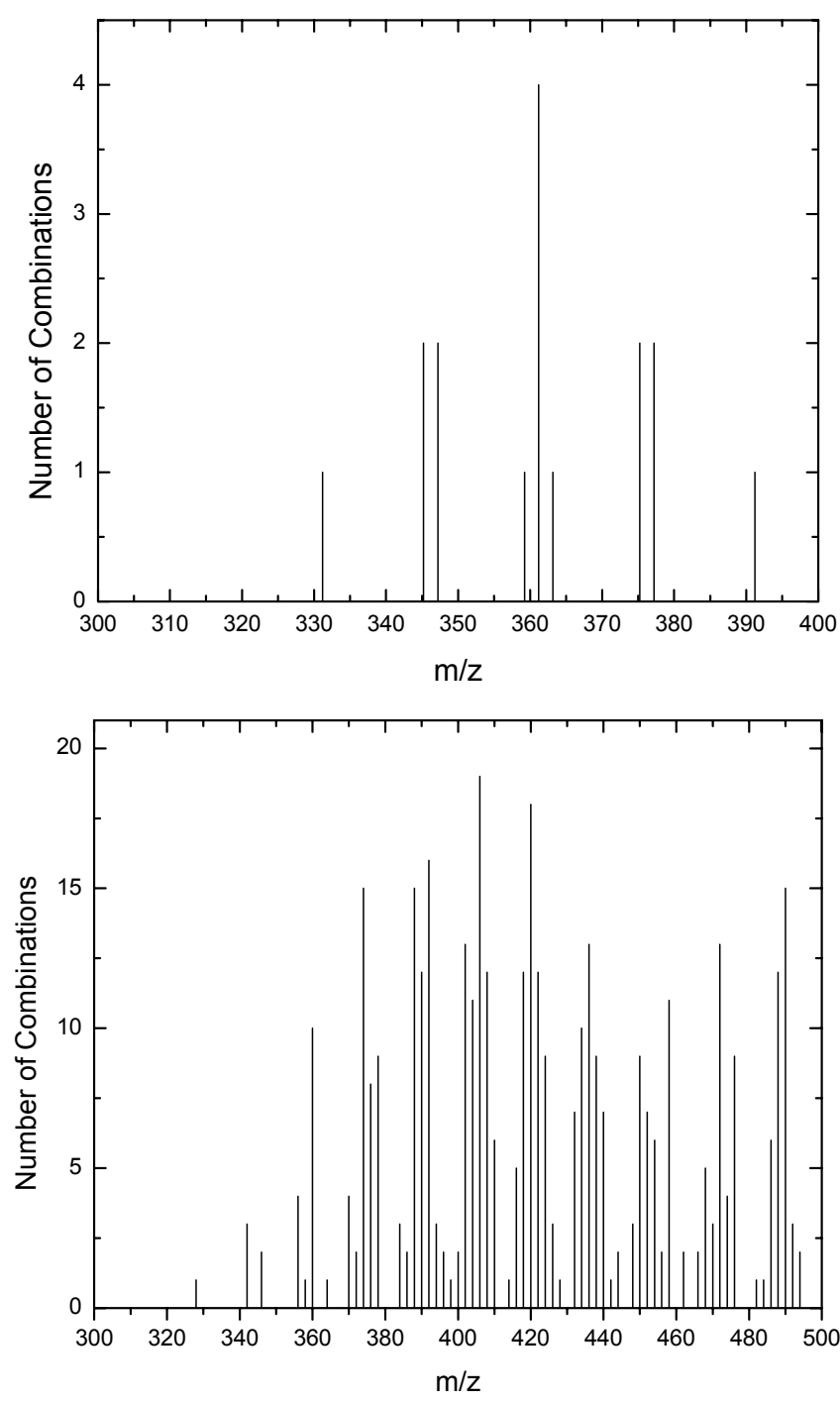

Figure S2. 
es035030r-Supporting Information

page $\mathrm{S} 4$

$\# 4$

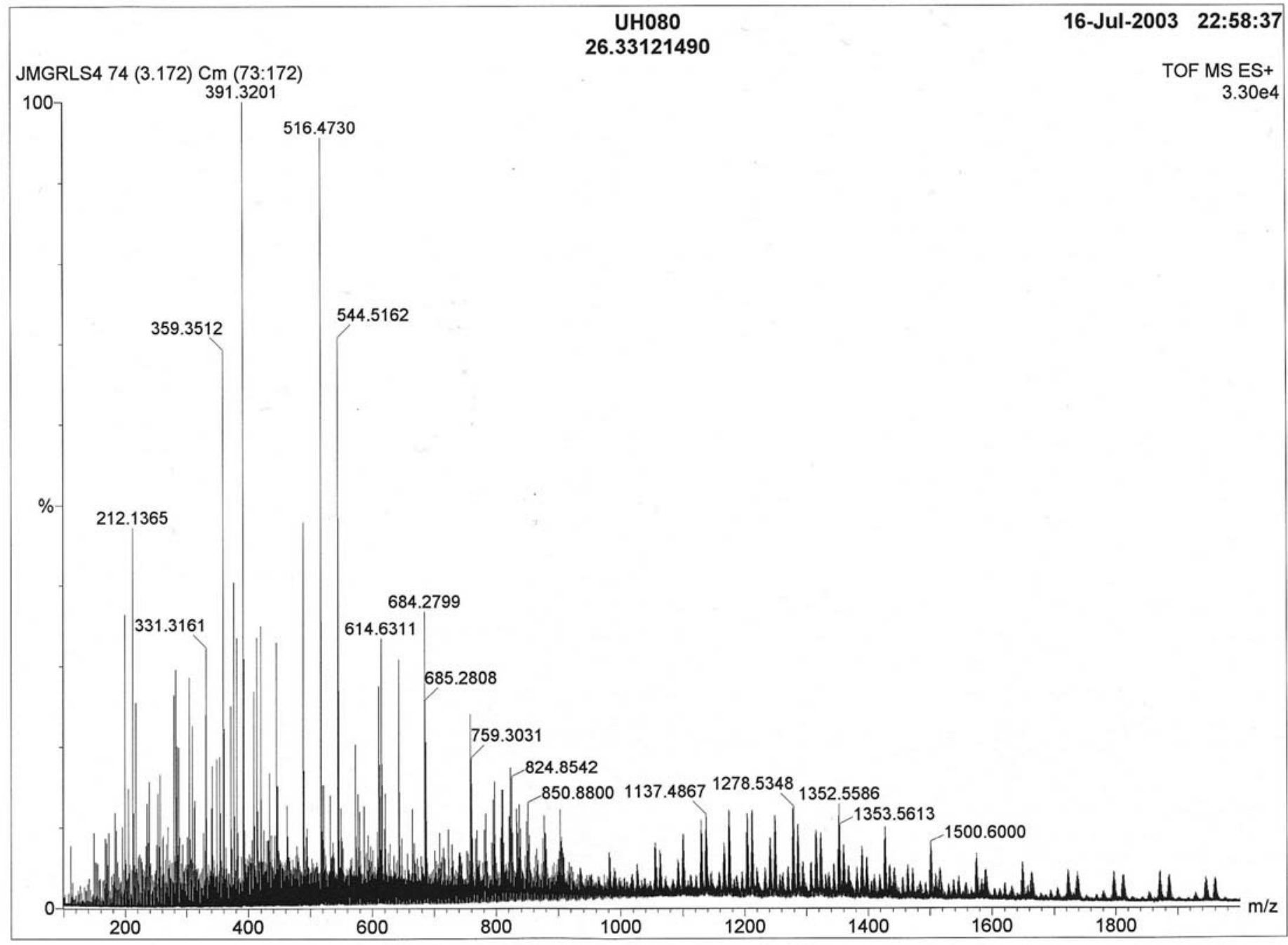

Figure S3. 
es035030r-Supporting Information

page $\mathrm{S} 5$

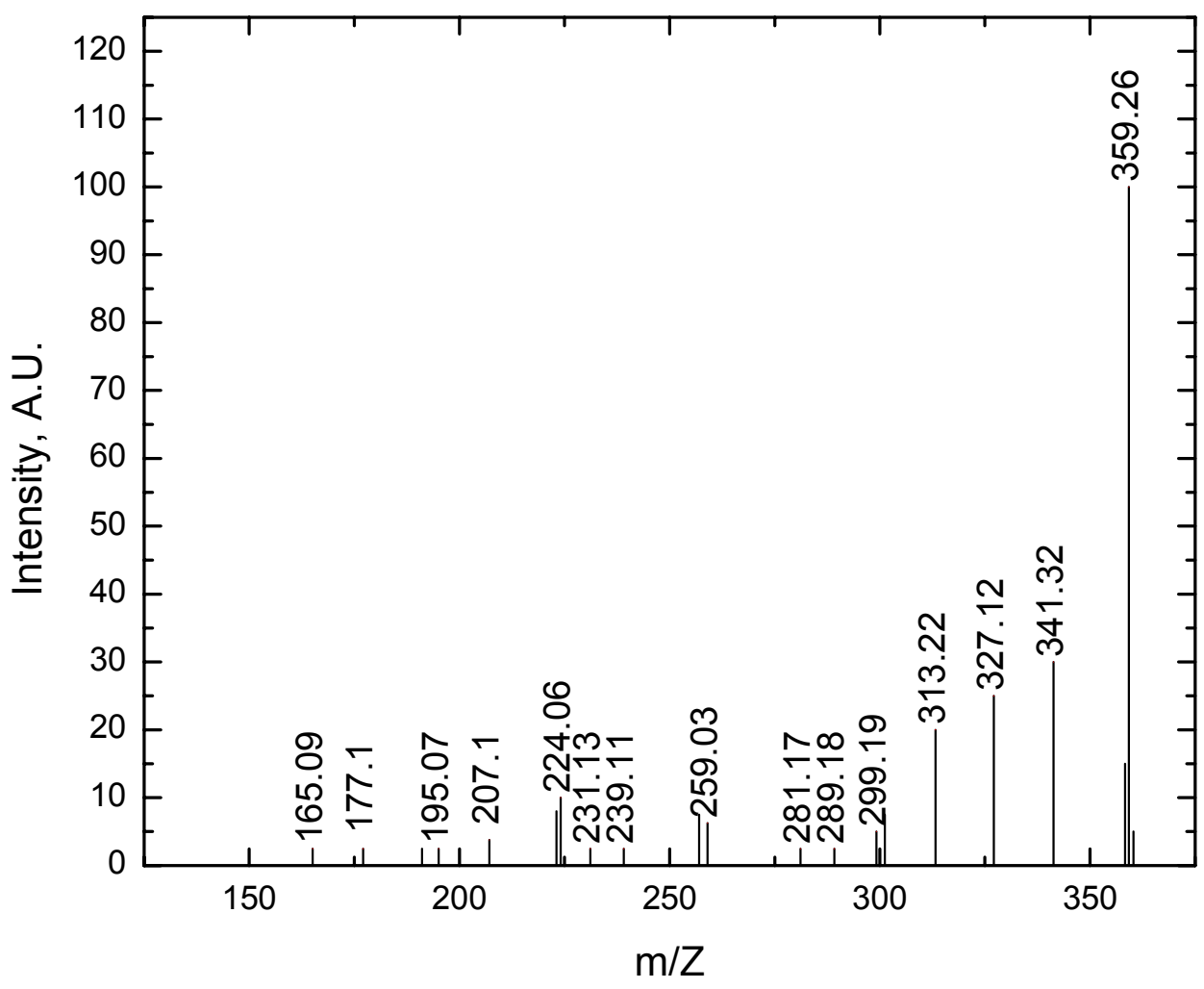

Figure S4. 